\title{
Influence of 2000-2050 climate change on particulate matter in the United States: results from a new statistical model
}

\section{Lu Shen et al.}

Correspondence to: Lu Shen (lshen@fas.harvard.edu)

The copyright of individual parts of the supplement might differ from the CC-BY 3.0 licence. 


\section{Supplement}

Table S1. Models from the Coupled Model Intercomparison Project Phase 5 (CMIP5) used for this study.

\begin{tabular}{|c|c|}
\hline Model Name & Institute \\
\hline ACCESS1-0 & $\begin{array}{l}\text { Commonwealth Scientific and Industrial Research,Organization (CSIRO) and Bureau of } \\
\text { Meteorology (BOM), Australia }\end{array}$ \\
\hline BCC-CSM1-1 & Beijing Climate Center, China Meteorological Administration \\
\hline BNU-ESM & College of Global Change and Earth System Science, Beijing Normal University \\
\hline CanESM2 & Canadian Centre for Climate Modelling and Analysis \\
\hline CNRM-CM5 & $\begin{array}{l}\text { Centre National de Recherches Météorologiques / Centre Européen de Recherche et } \\
\text { Formation Avanwcée en Calcul Scientifique }\end{array}$ \\
\hline CSIRO-Mk3.6.0 & $\begin{array}{l}\text { Commonwealth Scientific and Industrial Research Organization in collaboration with } \\
\text { Queensland Climate Change Centre of Excellence }\end{array}$ \\
\hline GFDL-CM3 & NOAA Geophysical Fluid Dynamics Laboratory \\
\hline GISS-E2-R & NASA Goddard Institute for Space Studies \\
\hline HadGEM2-CC & $\begin{array}{l}\text { Met Office Hadley Centre (additional HadGEM2-ES realizations contributed by Instituto } \\
\text { Nacional de Pesquisas Espaciais) }\end{array}$ \\
\hline HadGEM2-ES & $\begin{array}{l}\text { Met Office Hadley Centre (additional HadGEM2-ES realizations contributed by Instituto } \\
\text { Nacional de Pesquisas Espaciais) }\end{array}$ \\
\hline INM-CM4 & Institute for Numerical Mathematics \\
\hline IPSL-CM5A-LR & Institut Pierre-Simon Laplace \\
\hline IPSL-CM5A-MR & Institut Pierre-Simon Laplace \\
\hline IPSL-CM5B-LR & Institut Pierre-Simon Laplace \\
\hline MIROC-ESM & $\begin{array}{l}\text { Japan Agency for Marine-Earth Science and Technology, Atmosphere and Ocean Research } \\
\text { Institute (The University of Tokyo), and National Institute for Environmental Studies }\end{array}$ \\
\hline MIROC-ESM-CHEM & $\begin{array}{l}\text { Japan Agency for Marine-Earth Science and Technology, Atmosphere and Ocean Research } \\
\text { Institute (The University of Tokyo), and National Institute for Environmental Studies }\end{array}$ \\
\hline MIROC5 & $\begin{array}{l}\text { Atmosphere and Ocean Research Institute (The University of Tokyo), National Institute for } \\
\text { Environmental Studies, and Japan Agency for Marine-Earth Science and Technology }\end{array}$ \\
\hline MRI-CGCM3 & Meteorological Research Institute \\
\hline NorESM1-M & Norwegian Climate Centre \\
\hline
\end{tabular}


Table S2. Models from the Atmospheric Chemistry and Climate Model Intercomparison Project (ACCMIP) used for this study (Lamarque et al, 2013).

\begin{tabular}{llll}
\hline Model & Type & Resolution(lat/lon/\#levels), top level & Modelling Center \\
\hline NCAR-CAM3.5 & CCM & $1.875 / 2.5 / \mathrm{L} 26,3.5 \mathrm{hPa}$ & NCAR,USA \\
GFDL-AM3 & CCM & $2 / 2.5 / \mathrm{L} 48,0.017 \mathrm{hPa}$ & UCAR/NOAA,GFDL, USA \\
MIROC-CHEM & $\mathrm{CCM}$ & $2.8 / 2.8 / \mathrm{L} 80,0.003 \mathrm{hPa}$ & FRCGC, JMSTC Japan \\
GISS-ModelE2* & $\mathrm{CCM}$ & $2 / 2.5 / \mathrm{L} 40,0.14 \mathrm{hPa}$ & NASA-GISS,USA
\end{tabular}

*We use an updated GISS simulation relative to their ACCMIP contributions, forced in atmospher-only mode using the ACCMIP emissions (Lamarque et al., 2010), observed daily sea-surface temperatures and sea-ice from Reynolds et al. (2007), and with winds nudged to the Modern-Era Retrospective Analysis for Research and Applications (MERRA) meteorological reanalysis (Rienecker et al., 2011). 


\section{Cross-validation results in different seasons}

Cross-validatedd $\mathrm{R}^{2}$ between observed and predicted $\mathrm{PM}_{2.5}$ in different seasons

(a) MAM

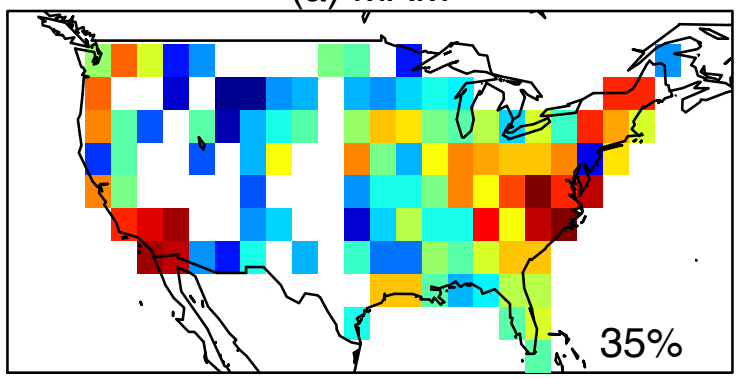

(c) SON

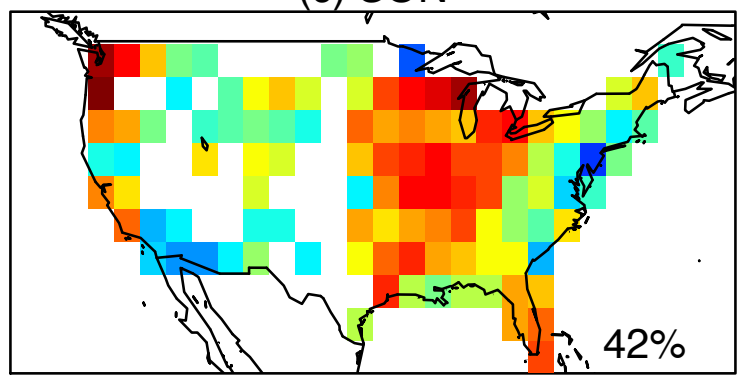

(b) JJA

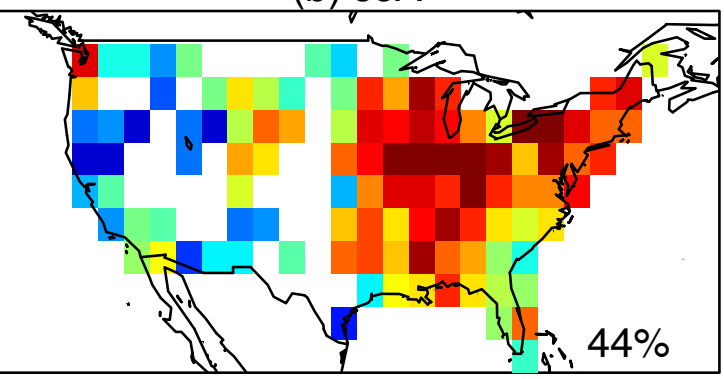

(d) DJF

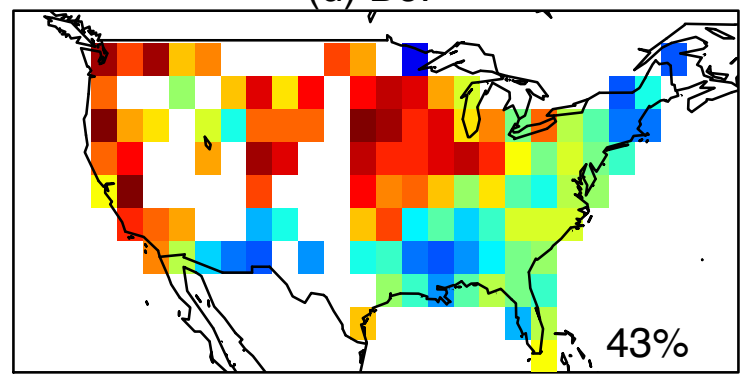

$\mathrm{R}^{2}$

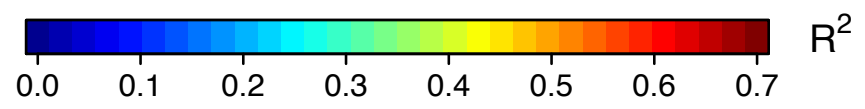

Figure S1. Cross-validated coefficients of determination $\left(R^{2}\right)$ between observed and predicted 1999-2013 monthly $\mathrm{PM}_{2.5}$ in different seasons across the United States, calculated with both local meteorology and patterns of synoptic circulation. Spatially averaged coefficients of determination are shown inset. 
2. Distribution of variance inflation factors (VIFs)

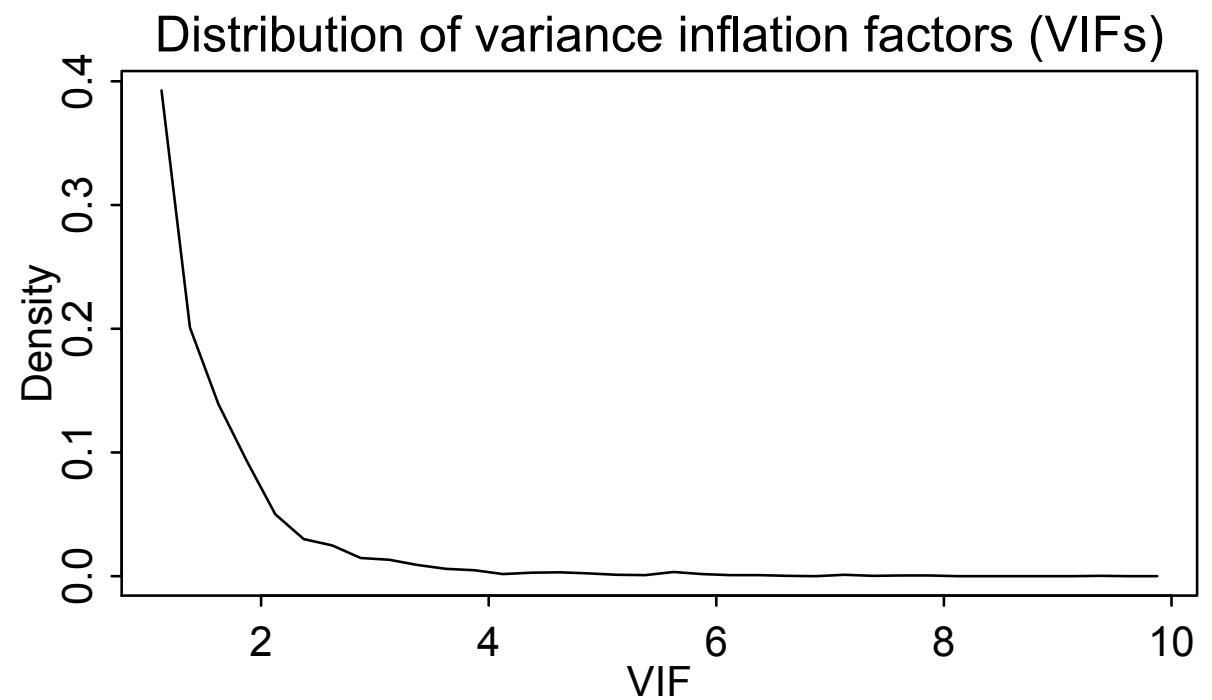

Figure S2. The distribution of variance inflation factors (VIFs) of all variables in each gridbox and each month, calculated from the regression model using the best variable combination of both local meteorology and synoptic patterns. 
3. Changes of meteorological variables from 2000 to 2050

JJA 2000-2050 changes in meteorological variables

(a) Surface temperature

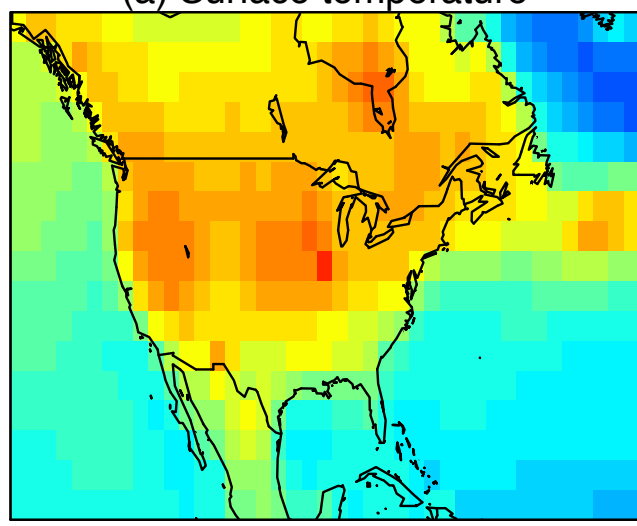

(c) Precipitation
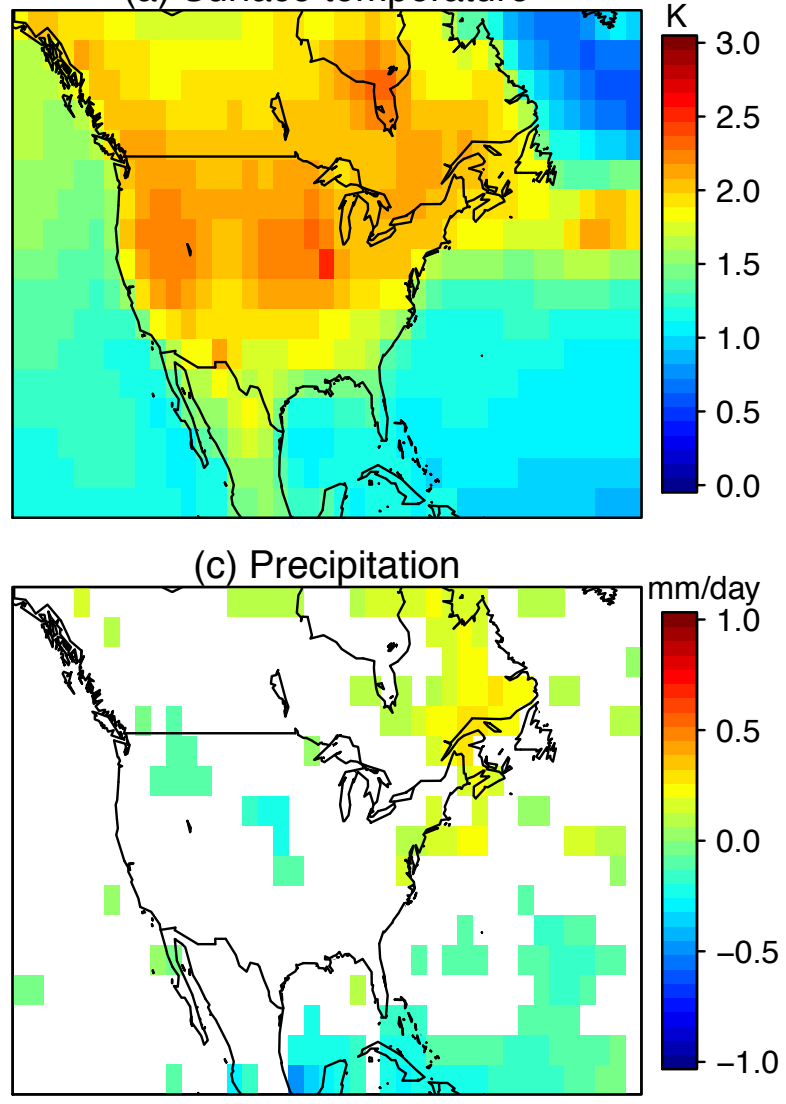

(b) Relative humidity
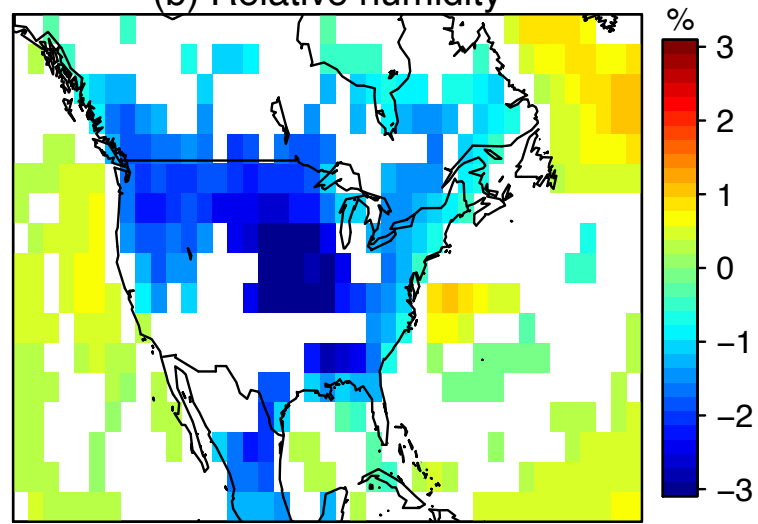

(d) Surface wind

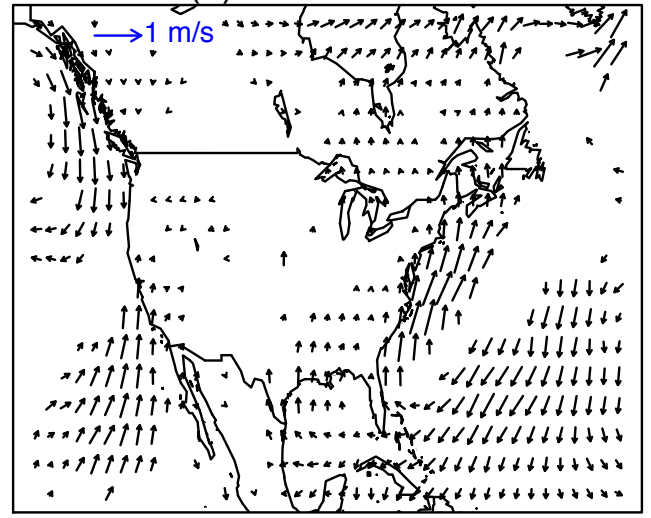

Figure S3. Seasonal changes in June-July-August (a) mean temperature, (b) relative humidity, (c) precipitation and (d) surface wind field from 2000-2019 to 2050-2069, as projected by 19 CMIP5 climate models following the RCP4.5 scenario. White space indicates regions where fewer than 14 of the models show a consistent sign of change. 
DJF 2000-2050 changes in meteorological variables

(a) Surface temperature
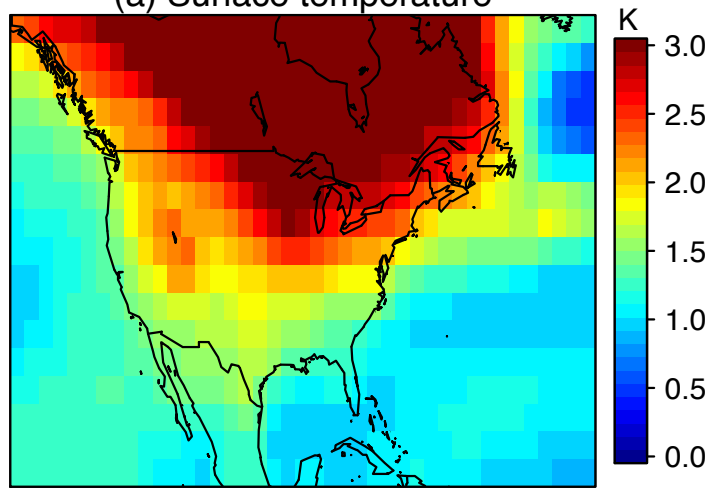

(c) Precipitation

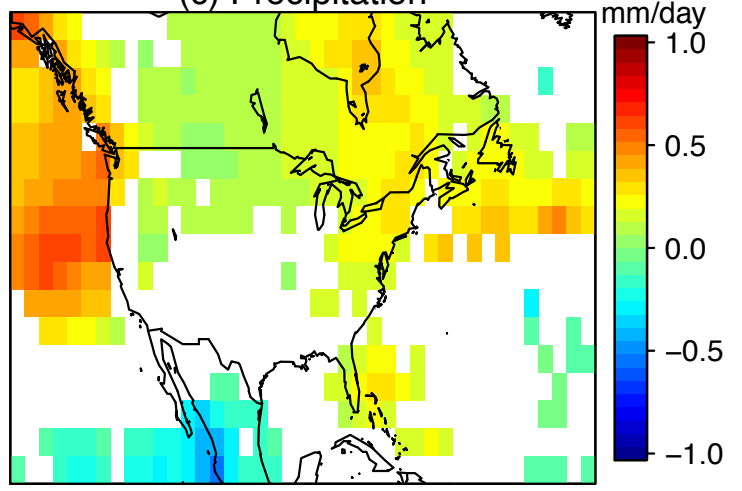

(b) Relative humidity

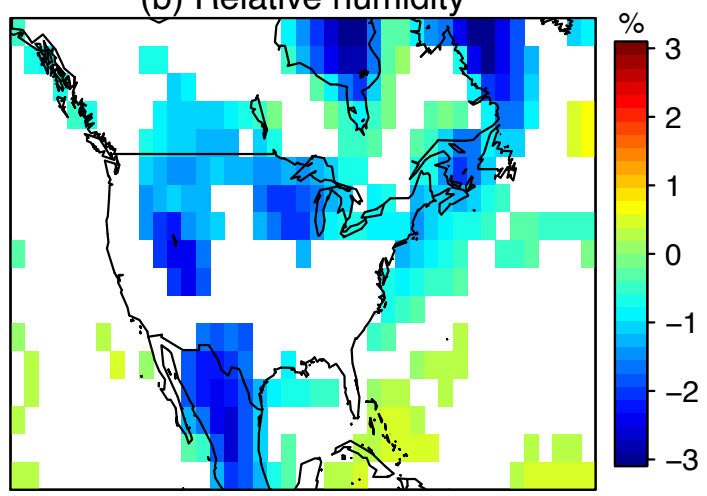

(d) Surface wind

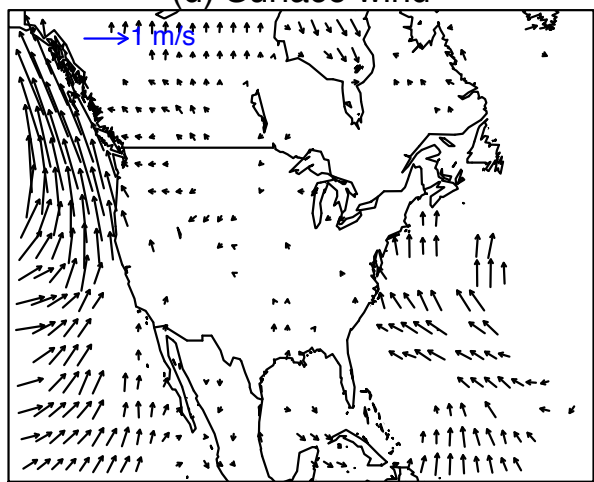

Figure S4. Same as Figure S3 but for December-January-February. 


\section{Projected $\mathrm{PM}_{2.5}$ changes in each CMIP5 model}

Effects of 2050s climate change on annual mean $\mathrm{PM}_{2.5}$ in each CMIP5 model
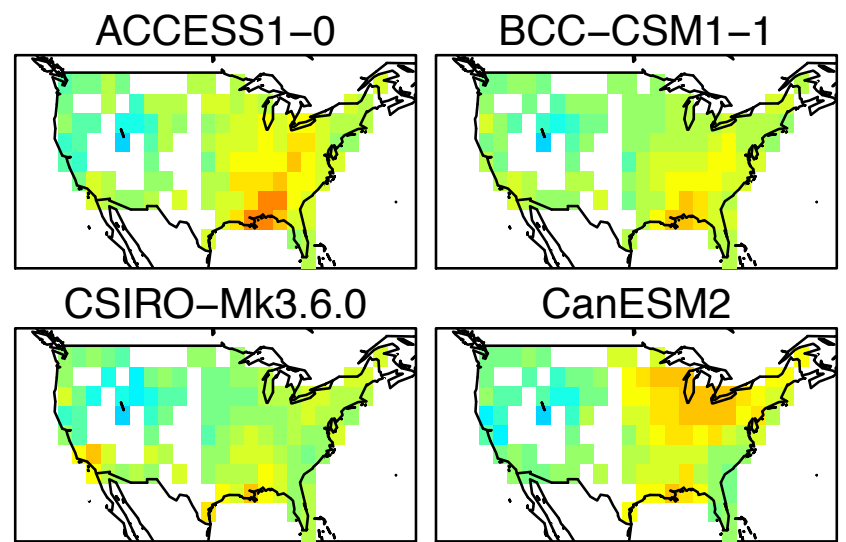

HadGEM2-CC

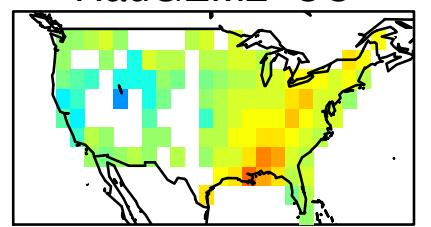

IPSL-CM5A-MR

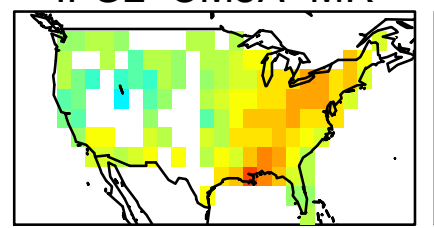

MIROC5

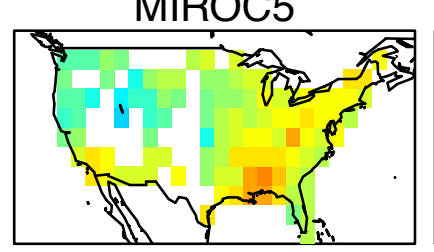

CanESM2
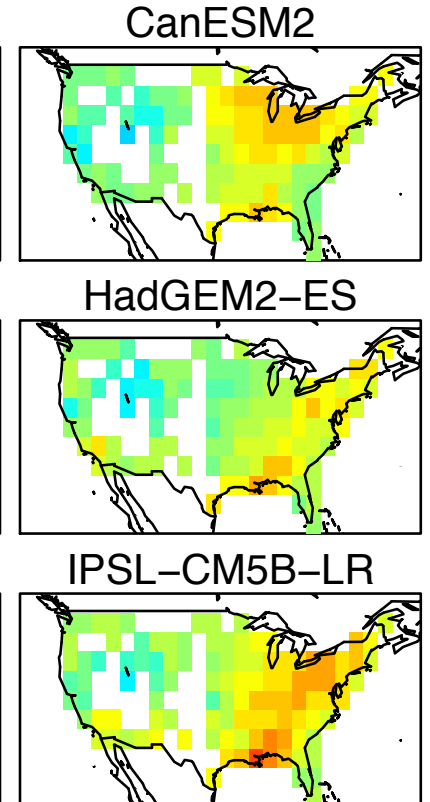

MRI-CGCM3

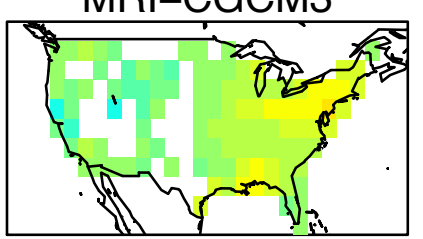

BNU-ESM

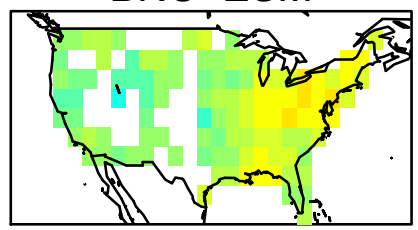

GFDL-CM3

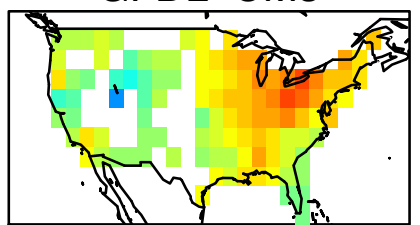

INM-CM4
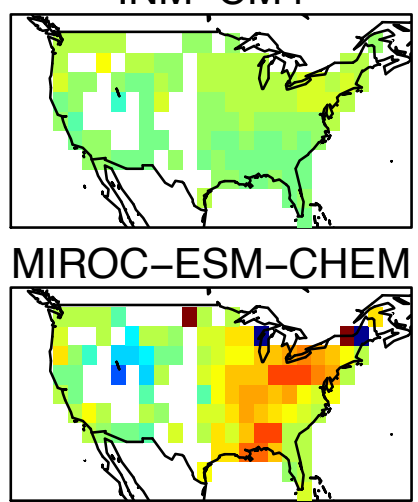

NorESM1-M

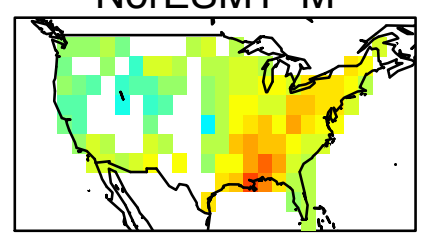

CNRM-CM5

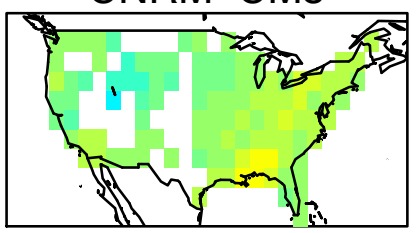

GISS-E2-H

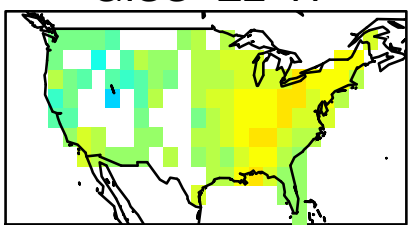

IPSL-CM5A-LR
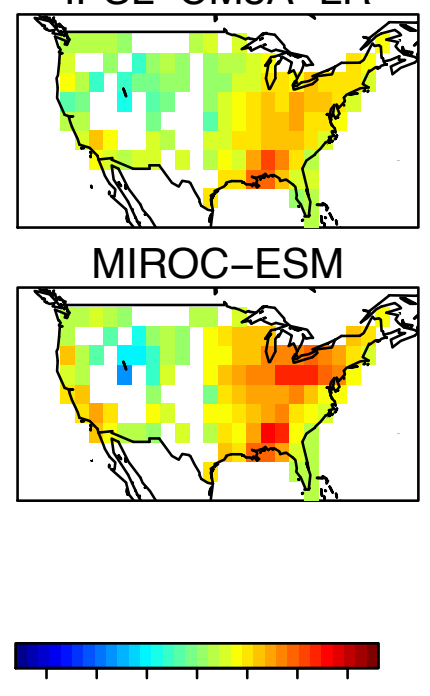

$\begin{array}{rrrrrr}-3 & -2 & -1 & 0 & 1 & 2 \\ & & & \\ \text { unit: } & \mu \mathrm{g} \mathrm{m}^{-3}\end{array}$

Figure S5. Effects of climate change from 2000-2019 to 2050-2069 on annual mean $\mathrm{PM}_{2.5}$ concentrations, calculated with observed relationships of $\mathrm{PM}_{2.5}$ and meteorology and with meteorology projected by each of the 19 CMIP5 models. White areas denote the regions with no $\mathrm{PM}_{2.5}$ observations. For those models providing an ensemble of simulations for the RCP4.5 scenario, only one simulation was chosen for application to our model. 
5. The $90^{\text {th }}$ and $10^{\text {th }}$ percentile changes in annual mean $P M_{2.5}$ by $2050 \mathrm{~s}$

The 90 th\% change of annual mean $\mathrm{PM}_{2.5}$ by 2050 s

(a) MAM

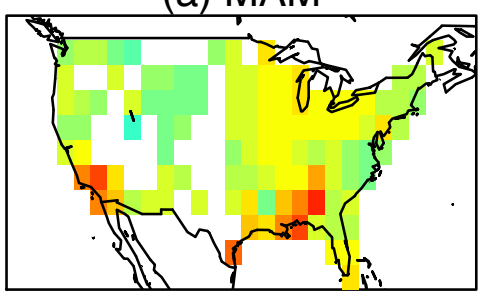

(d) DJF

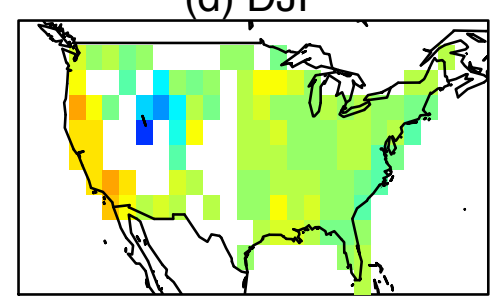

(b) JJA

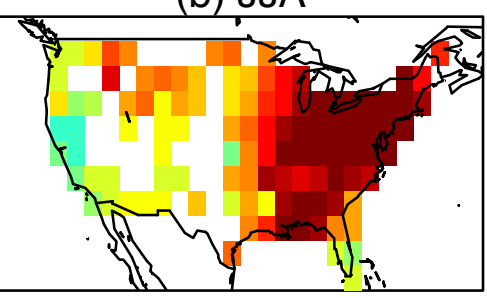

(e) Annual

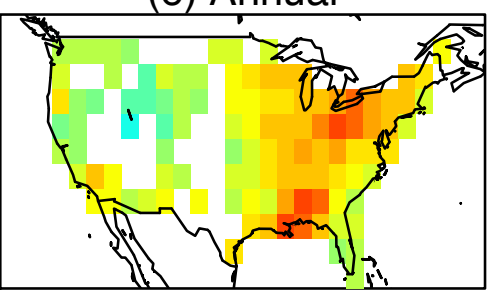

(c) SON
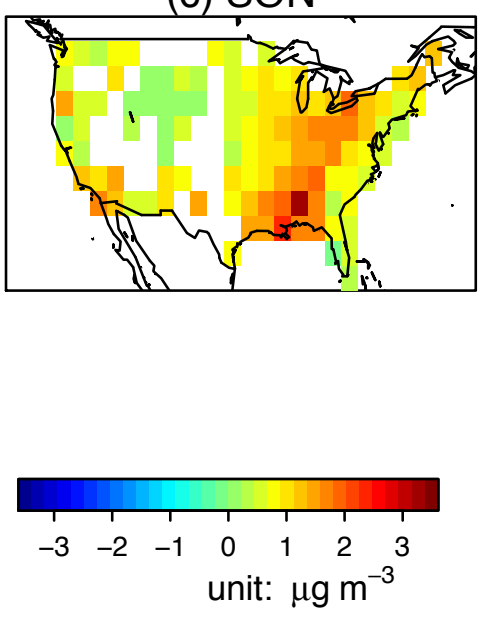

Figure S6. Same as Figure 4, but for the $90^{\text {th }}$ percentile changes of $\mathrm{PM}_{2.5}$ concentrations, calculated with meteorology projected by the ensemble of 19 CMIP5 models.

The 10 th $\%$ change of annual mean $\mathrm{PM}_{2.5}$ by 2050 s

(a) MAM

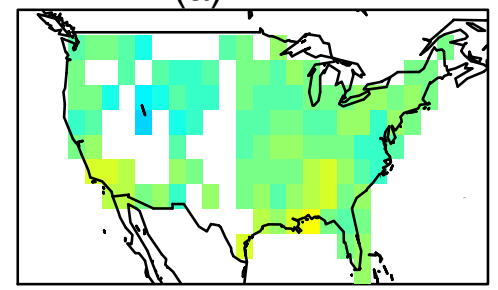

(d) DJF

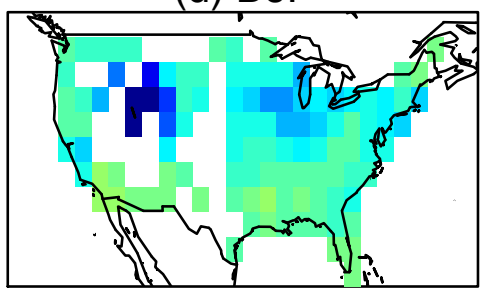

(b) JJA

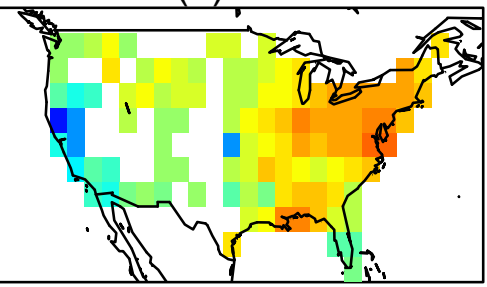

(e) Annual

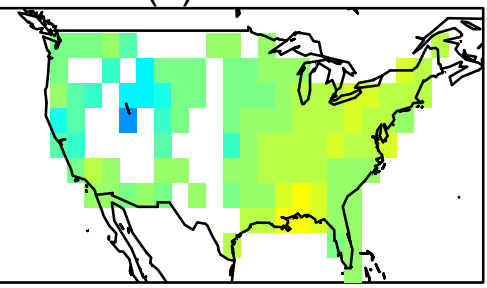

(c) SON
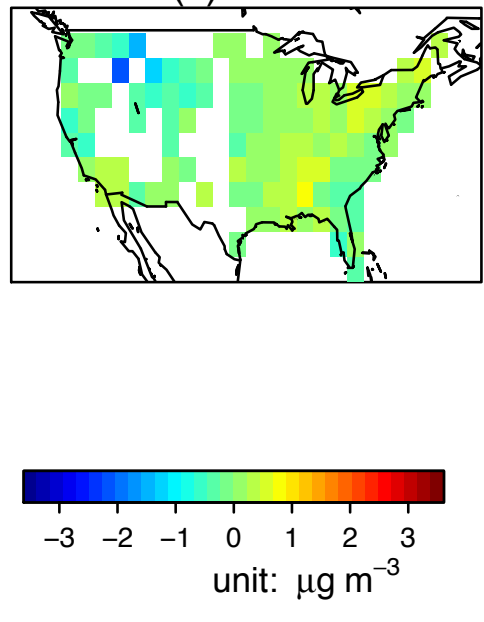

Figure S7. Same as Figures 4 and $\mathrm{S} 7$, but for the $10^{\text {th }}$ percentile changes of $\mathrm{PM}_{2.5}$ concentrations, calculated with meteorology projected by the ensemble of 19 CMIP5 models. 
6. Time series of regional $\mathrm{PM}_{2.5}$ changes from 2000 to 2069

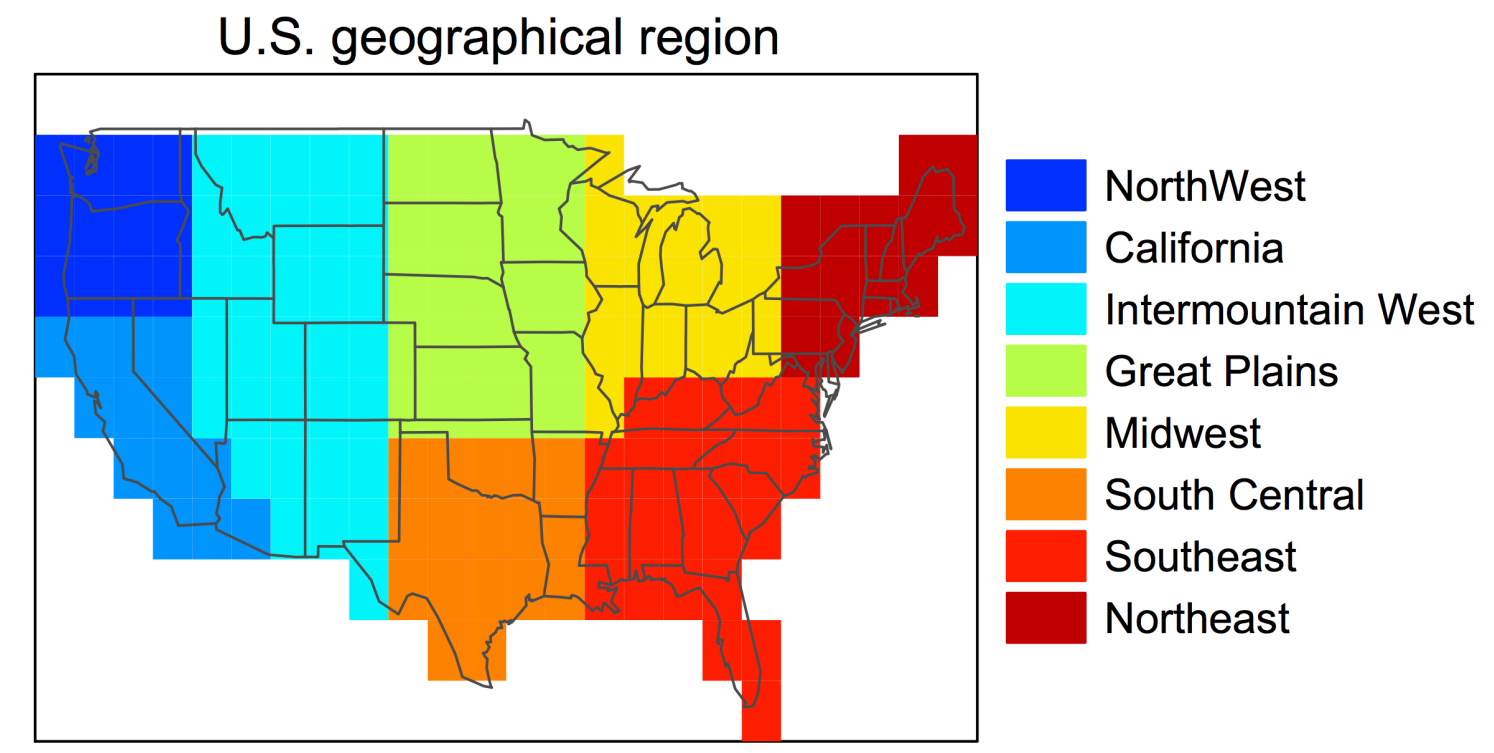

Figure S8. The eight U.S. geographical regions used for Figures S9-11. 
Regional changes of annual mean $\mathrm{PM}_{2.5}$ from 2000 to 2069
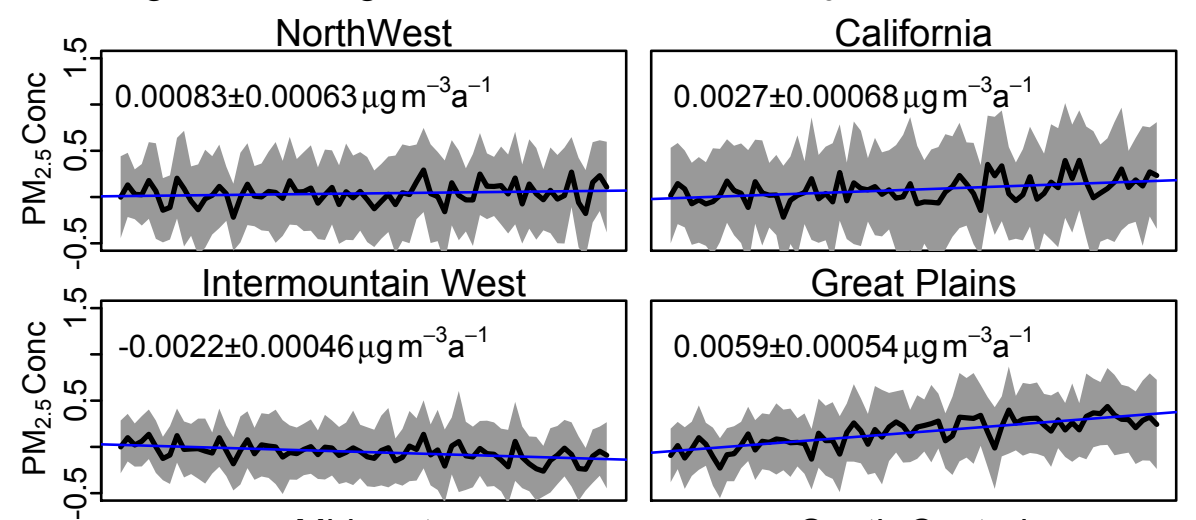

Great Plains
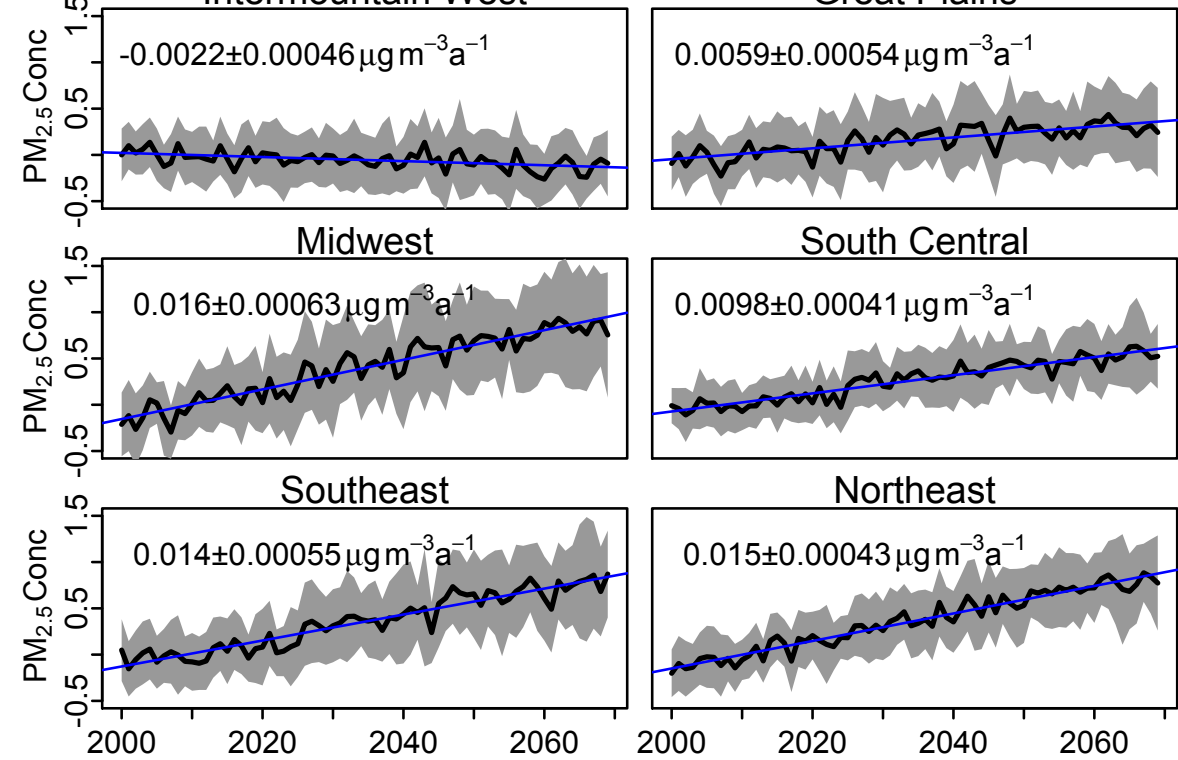

South Central

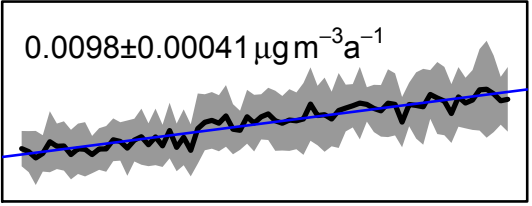

Northeast

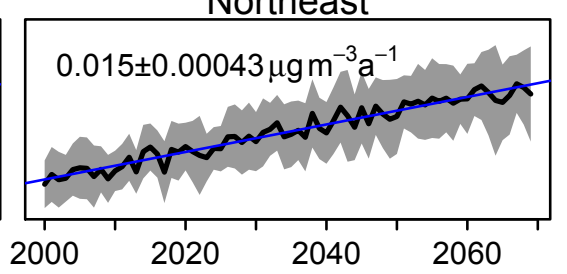

Figure S9. Regional trends in annual mean $\mathrm{PM}_{2.5}$ concentrations from 2000 to 2069, calculated with observed relationships of $\mathrm{PM}_{2.5}$ and meteorology and with meteorology projected by an ensemble of 19 CMIP5 models. Shading denotes one standard deviation the mean change across models. For those regions with significant trends in $\mathrm{PM}_{2.5}$, the slopes of the timeseries over the 70-yr timeframe are shown inset. Figure S8 defines the eight regions. 
Regional changes of JJA PM 2.5 from 2000 to 2069 NorthWest

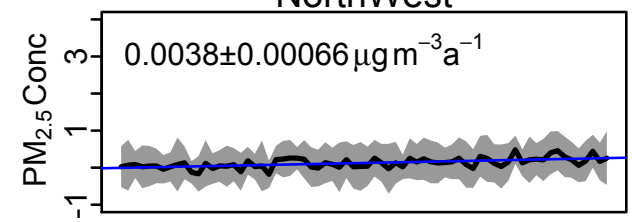

California

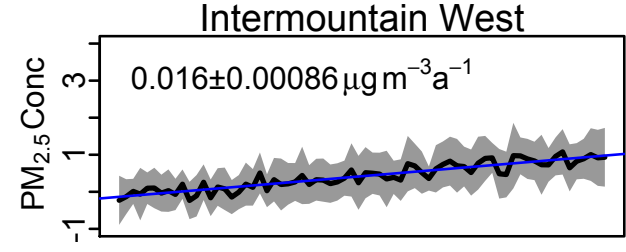

Midwest

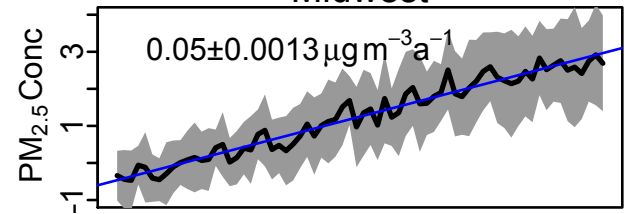

Southeast
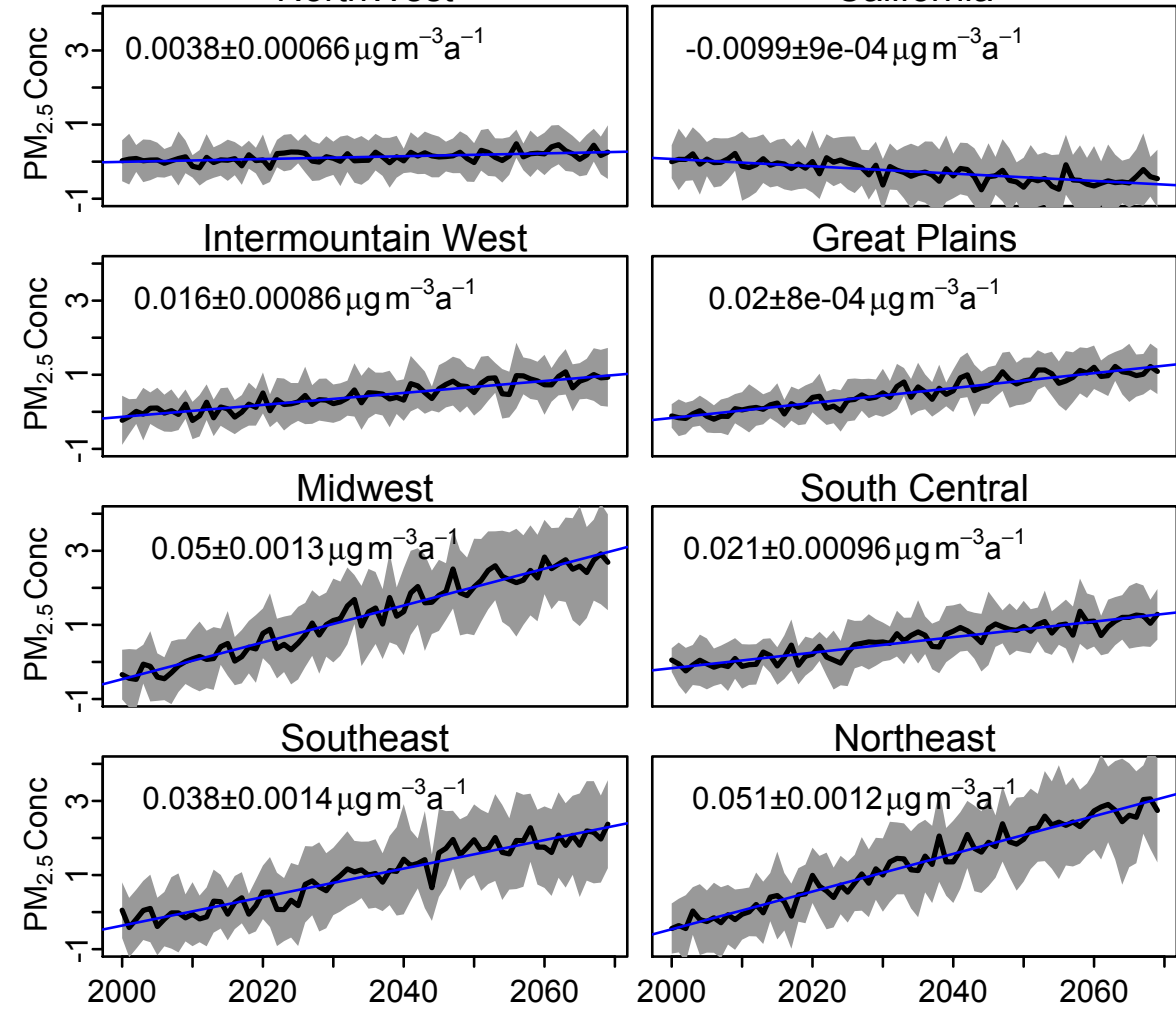

Great Plains

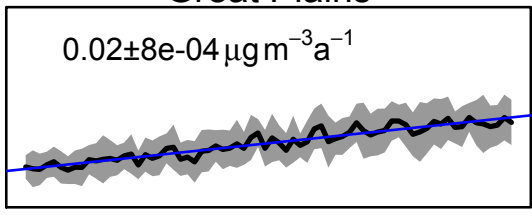

South Central

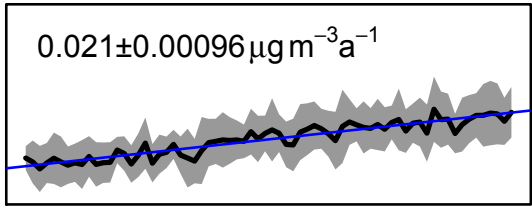

Northeast

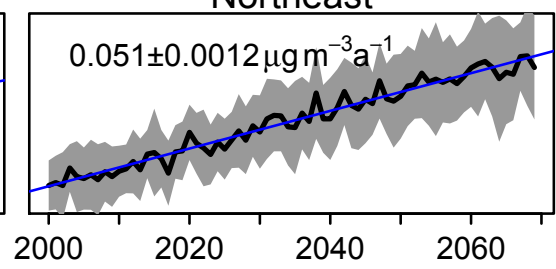

Figure S10. Similar as Figure S9, but for trend in JJA PM 2.5 concentrations. 
Regional changes of DJF $\mathrm{PM}_{2.5}$ from 2000 to 2069 NorthWest

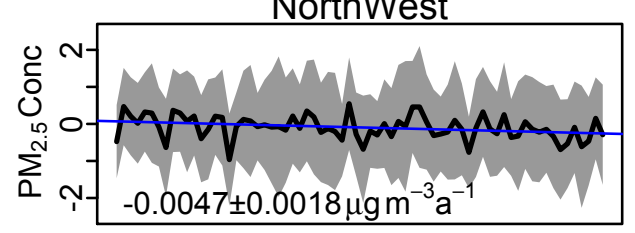

California

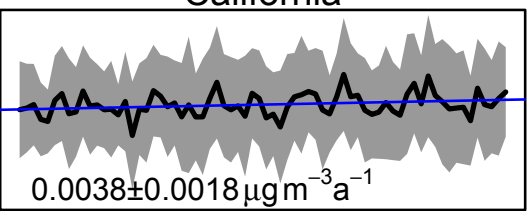

Intermountain West

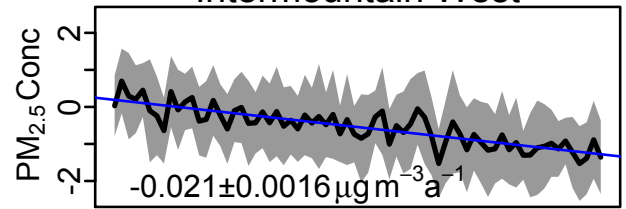

Great Plains

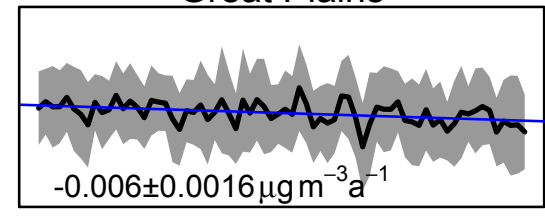

Midwest

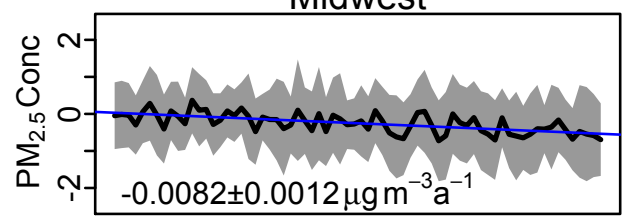

South Central

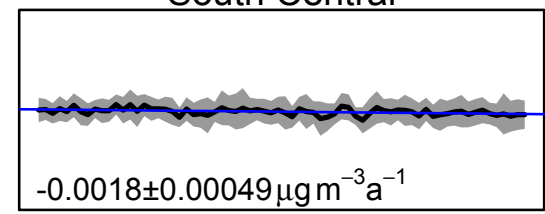

Southeast

Northeast
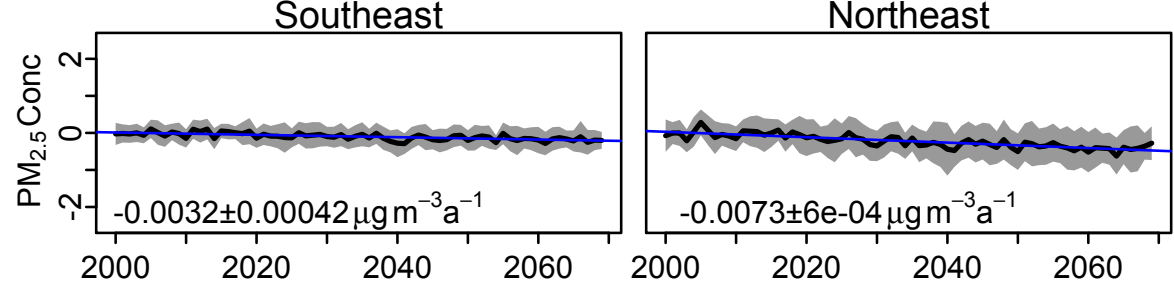

Figure S11. Similar as Figure S9, but for trends in DJF $\mathrm{PM}_{2.5}$ concentrations. 
7. Projected $\mathbf{P M}_{2.5}$ changes in the future climate excluding the influence from changing temperature.

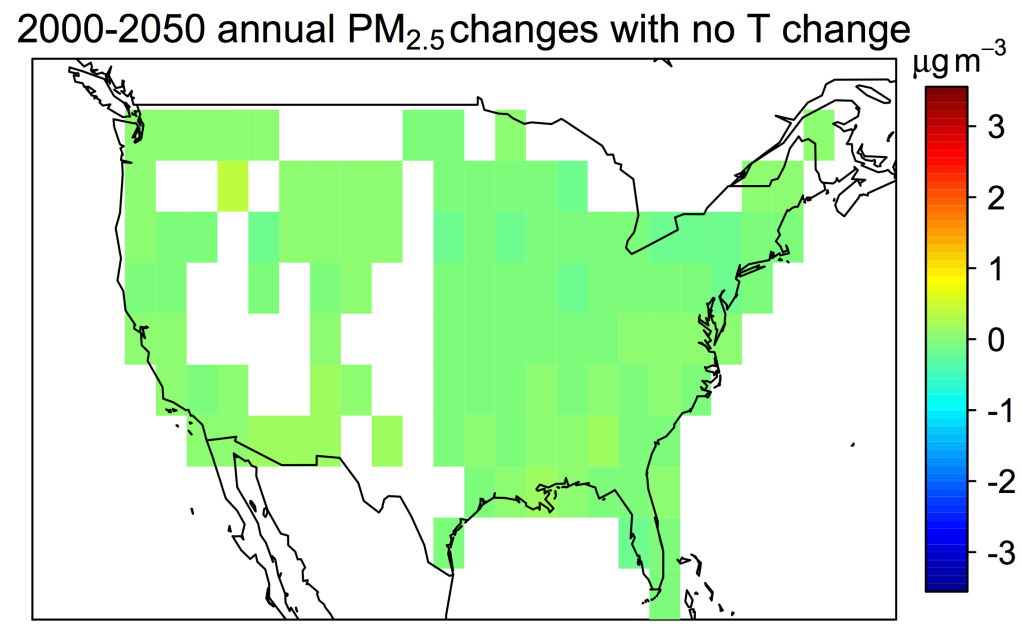

Figure S12. Response of annual mean $\mathrm{PM}_{2.5}$ concentrations to 2000-2050 climate change when changes in surface temperature are excluded. The figure shows the mean response as projected by an ensemble of 19 CMIP5 models. For this sensitivity test, surface temperatures in the statistical model for 2050-2069 are kept the same as for 2000-2019. White areas indicate regions with no $\mathrm{PM}_{2.5}$ observations. 


\section{Slopes of JJA PM 2.5 and temperature in 1999-2006 and 2007-2013}

Slopes of JJA PM 2.5 and temperature in AQS for 1999-2006 and $2007-2013\left(\mu^{\left.-3 ~ m^{-3} \mathrm{~K}^{-1}\right)}\right.$
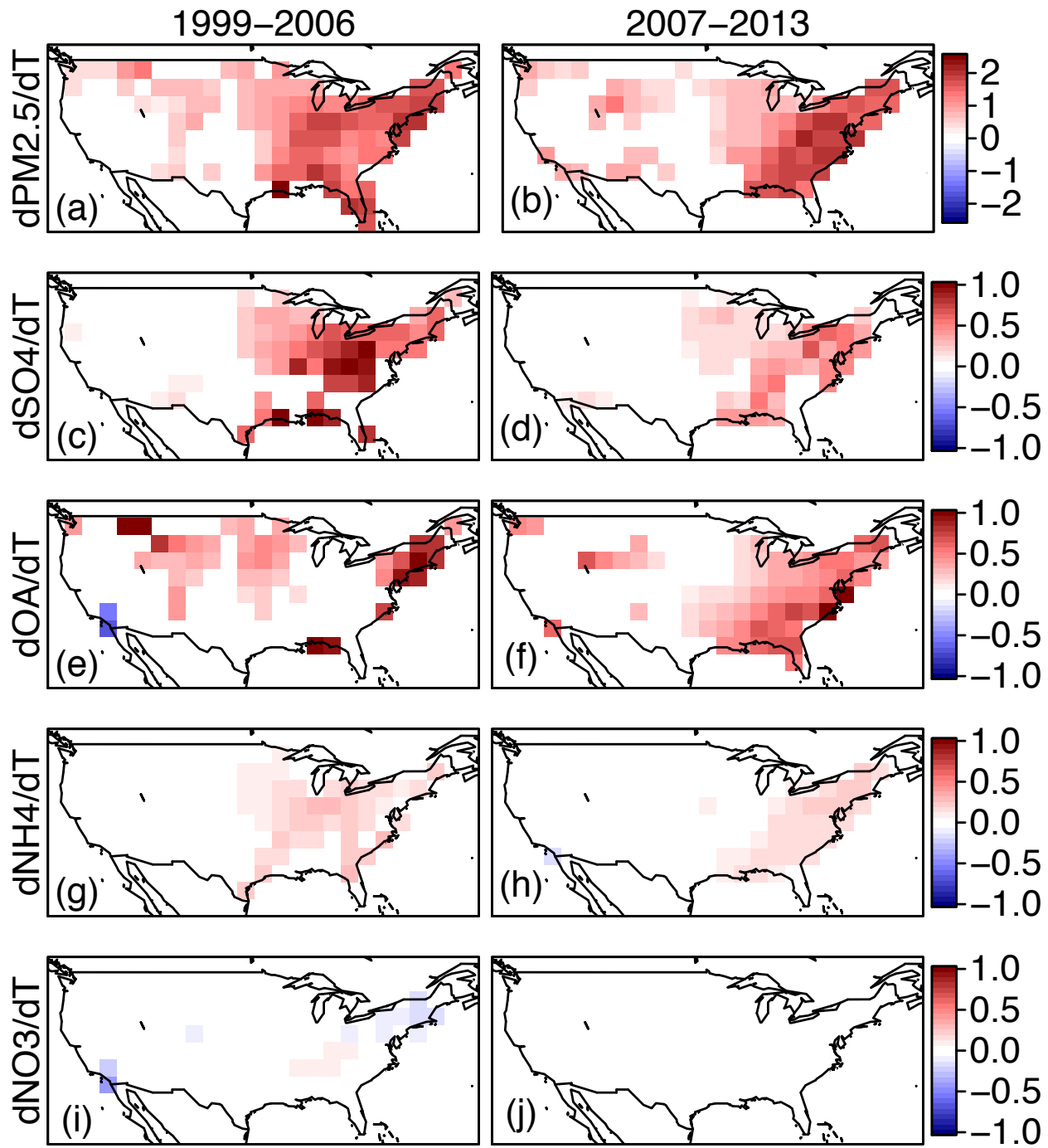

Figure S13. The slopes of detrended (a-b) monthly mean $\mathrm{PM}_{2.5}$ and (c-j) different $\mathrm{PM}_{2.5}$ components with surface air temperature for 1999-2013 summer months. Left column shows slopes for 1999-2006 with relatively high NOx emissions, and right column shows slopes for 2007-2013 with relatively low NOx emissions. Organic aerosol (OA) in Panel (e-f) is inferred from the measured organic carbon (OC) component using an OA/OC mass ratio of 1.8 (Canagaratna et al., 2015 ). White areas indicate either missing data or grid boxes where the slope is not significant at the 0.10 level. We note that the observation network has fewer sites in 1999 and 2000 than more recent years. 